\title{
LPS-induced proinflammatory cytokine expression in human airway epithelial cells and macrophages via NF-кB, STAT3 or AP-1 activation
}

\author{
XUEFANG LIU ${ }^{1,2}$, SUGAI YIN ${ }^{1,2}$, YULONG CHEN ${ }^{1,2}$, YAOSONG WU ${ }^{1,2}$, WANCHUN ZHENG $^{1,2}$, \\ HAORAN DONG $^{1,2}$, YAN BAI ${ }^{1,2}$, YANQIN QIN ${ }^{1,2}$, JIANSHENG LI ${ }^{1,2}$, SUXIANG FENG $^{1,2}$ and PENG ZHAO ${ }^{1,2}$ \\ ${ }^{1}$ Henan Key Laboratory of Chinese Medicine for Respiratory Disease; ${ }^{2}$ Collaborative Innovation Center \\ for Respiratory Disease Diagnosis and Treatment and Chinese Medicine Development of Henan Province, \\ Henan University of Chinese Medicine, Zhengzhou, Henan 450046, P.R. China
}

Received October 10, 2016; Accepted June 1, 2017

DOI: $10.3892 / \mathrm{mmr} .2018 .8542$

\begin{abstract}
Lipopolysaccharide (LPS), the major outer surface membrane component of Gram-negative bacteria, is one of the main etiological factors in the pathogenesis of several lung diseases, such as chronic obstructive pulmonary disease. The respiratory epithelium and the macrophages comprise the dynamic interface between the outside environment and the host response to bacterial infection via cytokine secretion. In the present study, the mechanisms of LPS induced-inflammatory response in human lung cells and macrophages were investigated. The effects of LPS exposure on cytokine production, inflammation-related transcription factors and intracellular signaling pathway activation were assessed in human lung mucoepidermoid carcinoma H292 cells and human macrophage THP-1 cells. The results demonstrated that LPS markedly increased the expression of interleukin (IL)-6, IL-8, tumor necrosis factor (TNF)- $\alpha$, matrix metallopeptidase (MMP)-9 and tissue inhibitor of metalloproteinases-1 in H292 cells, while it increased the production of IL-6, IL-8 and TNF- $\alpha$ in differentiated THP-1 cells. In addition, LPS exposure activated nuclear factor (NF)- $\kappa \mathrm{B}$ and activator protein (AP)-1 signaling in $\mathrm{H} 292$ cells, while it activated NF- $\mathrm{KB}$ and signal transducer and activator of transcription (STAT) 3 signaling in THP-1 cells. Furthermore, treatment with NF- $\kappa$ B, AP-1 or STAT3 inhibitors significantly decreased the LPS-mediated expression of IL- 8 and TNF- $\alpha$ in these cells, suggesting that these pathways might serve crucial roles in LPS-induced cytokine expression. In conclusion, LPS stimulation of H292 and THP-1 cells induced cytokine expression and $\mathrm{NF}-\kappa \mathrm{B}$,
\end{abstract}

Correspondence to: Professor Jiansheng Li, Henan Key Laboratory of Chinese Medicine for Respiratory Disease, Henan University of Chinese Medicine, 156 Jinshui Dong Road, Zhengzhou, Henan 450046, P.R. China

E-mail: 1i_js8@163.com

Key words: lipopolysaccharide, inflammatory responses, human bronchiolar epithelial cells, macrophage cells mitogen-activated protein kinase and Janus kinase/STAT3 pathway activation with subsequent nuclear translocation of NF- $\mathrm{B}$, AP-1 and STAT3, which demonstrated potential of the use of NF- $\mathrm{NB}, \mathrm{AP}-1$ and STAT3 in therapies for conditions and diseases associated with chronic inflammation.

\section{Introduction}

Airway inflammatory diseases, such as chronic obstructive pulmonary disease (COPD) and asthma, are major causes of morbidity and mortality in patients, and place a substantial burden on healthcare systems (1). Bacterial infection, cigarette smoking and air pollutants are implicated in the onset and progression of lung inflammation (2). Lipopolysaccharides (LPS) is the major outer surface membrane component of Gram-negative bacteria and a biologically active component present in cigarette smoke (3). Thus, LPS-mediated inflammatory response is a major lung inflammation source from exposure to both gram-negative bacterial infection and cigarette smoke. During this inflammatory response, macrophages first help in endocytosis of bacterium debris, followed by generation of inflammatory cytokines and expansion of the local inflammatory response $(4,5)$. In addition, the respiratory epithelium has an active role in the airway defense through the production of cytoprotective mucus and through coordinating local inflammation responses by producing proinflammatory cytokines. These cytokines, however, also result in bronchial maladaptations, including pulmonary dysfunction, increased mucin production and protease-antiprotease imbalance (6-8).

It has been reported that proinflammatory cytokine production is induced by many stimuli through the mitogen-activated protein kinase (MAPK), nuclear factor $(\mathrm{NF})-\kappa \mathrm{B}$ or Janus kinase (JAK)/signal transducer and activator of transcription (STAT3) signaling cascades. For instance, LPS-induced MAPK and JAK/STAT3 activation results in activation of the downstream transcriptional factors $\mathrm{NF}-\kappa \mathrm{B}$, activator protein (AP)-1, peroxisome proliferator-activated receptor (PPAR) and STAT3, which mediate the transcription and translation of proinflammatory genes (9-11). In the present study, in order to investigate the mechanisms of LPS induced-inflammatory 
response in airway epithelial and macrophage cells, the effects of LPS exposure on the expression of interleukin (IL)-6, IL-8, IL-10, tumor necrosis factor (TNF)- $\alpha$, matrix metallopeptidase (MMP)-9 and tissue inhibitor of metalloproteinases (TIMP)-1 were examined in human airway epithelial H292 cells and macrophage THP-1 cells. Subsequently, inflammation-related transcription factors and intracellular signaling pathways that may be involved in LPS-induced pro-inflammation cytokine production were explored.

\section{Materials and methods}

Cell culture. H292 human lung mucoepidermoid carcinoma cells and THP-1 human monocytic cells were obtained from the American Type Culture Collection (Manassas, VA, USA). The cells were maintained in RPMI-1640 (Beijing Solarbio Science and Technology Co., Ltd., Beijing, China) supplemented with $10 \%$ fetal calf serum (Gibco; Thermo Fisher Scientific, Inc., Waltham, MA, USA), penicillin $(100 \mathrm{U} / \mathrm{ml})$ and streptomycin $(100 \mathrm{mg} / \mathrm{ml})$, and incubated at $37^{\circ} \mathrm{C}$ with $5 \% \mathrm{CO}_{2}$. All experiments were performed with exponentially growing cells. For differentiation to a macrophage phenotype, THP-1 cells were adjusted to the desired concentrations for each experiment and incubated with $20 \mu \mathrm{M}$ phorbol myristate acetate (PMA) diluted in complete culture medium for $24 \mathrm{~h}$. Then, the cells were washed with serum-free RPMI-1640 medium prior to each experiment.

Cell viability assay. For the cell viability assay, H292 ( $2 \times 10^{4}$ cells/well) and THP- 1 cells $\left(1 \times 10^{4}\right.$ cells/well, pretreated with $20 \mu \mathrm{M}$ PMA) were plated in sextuplicate 96-well plates for $24 \mathrm{~h}$. The cells were then stimulated with the indicated concentrations of LPS for 6, 12, 24 and $48 \mathrm{~h}$. Normal complete RPMI-1640 media without LPS was used as a negative control. Subsequently, MTT solution was added for $4 \mathrm{~h}$, following which the supernatants were removed and $150 \mu$ l dimethyl sulfoxide was added to each well to dissolve the formazan crystals. The absorbance was measured at $570 \mathrm{~nm}$.

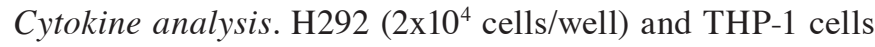
( $1 \times 10^{4}$ cells/well, pretreated with $20 \mu \mathrm{M}$ PMA) were seeded in triplicate into 96 -well tissue culture plates for $24 \mathrm{~h}$. The cells were then stimulated with 1,2 or $2.5 \mu \mathrm{g} / \mathrm{ml}$ of LPS for 6,12 , 24 and $48 \mathrm{~h}$. The levels of human cytokines were measured in the collected supernatants with human IL-6 (cat. no. EK0410), IL-8 (cat. no. EK0413), IL-10 (cat. no. EK0416), TNF- $\alpha$ (cat. no. EK0525), MMP-9 (cat. no. EK0465) and TIMP-1 (cat. no. EK0520) ELISA kits (Boster Biological Technology, Ltd., Wuhan, China), according to the manufacturer's protocols. For the inhibitor experiments, H292 and THP-1 cells were pretreated with pyrrolidine dithiocarbamate (PDTC), SP00125 or stattic (all Sigma-Aldrich; Merck KGaA, Darmstadt, Germany) for $4 \mathrm{~h}$, followed by exposure to LPS for $48 \mathrm{~h}$, prior to measuring IL- 8 and TNF- $\alpha$ levels in the cell culture supernatants with ELISA kits, as aforementioned.

Electrophoretic mobility shift assay (EMSA). Nuclear protein was extracted from LPS-stimulated H292 and THP-1 cells using a total nuclear protein extraction kit (Beyotime Institute of Biotechnology, Shanghai, China), according to the manufacturer's protocol. Protein concentration was measured with the bicinchoninic acid (BCA) method.

H292 and differentiated THP-1 cells were treated with LPS for $24 \mathrm{~h}$. The DNA binding activities of AP-1, PPAR, NF- $\kappa$ B and STAT3 in the nuclear extracts were assessed by EMSA using the EMSA kit (Beyotime Institute of Biotechnology, Haimen, China), according to the manufacturer's protocol. The sequences of the oligonucleotides used were as follows: AP1, forward 5'-CGCTTGATGACTCAGCCGGAA-3' and reverse 3'-GCGAACTACTGAGTCGGCCTT-5'; AP-1 mutated probe, forward 5'-CGCTTGATGACTTGGCCGGAA-3' and reverse 3'-GCGAACTACTGAACCGGCCTT-5'; PPAR, forward 5'-CAAAACTAGGTCAAAGGTCA-3' and reverse 3'-GTT TTGATCCAGTTTCCAGT-5'; PPAR mutated probe, forward 5'-CAAAACTAGCACAAAGCACA-3', 3'-GTTTTGATC GTGTTTCGTGT-5' and reverse STAT3, forward 5'-GAT CCTTCTGGGAATTCCTAGATC-3' and reverse 3'-CTA GGA AGACCCTTAAGGATCTAG-5'; STAT3 mutated probe, forward 5'-GATCCTTCTGGGCCGTCCTAGATC-3' and reverse 3'-CTAGGAAGACCCGGCAGGATCTAG-5'; $\mathrm{NF}-\kappa \mathrm{B}$, forward 5'-AGT TGAGGGGACTTTCCCAGG C-3' and reverse 3'-TCAACTCCCCTGAAAGGGTCCG-5'; $\mathrm{NF}-\kappa \mathrm{B}$ mutated probe, forward 5'-AGTTGAGGCGACTTT CCCAGGC-3' and reverse 3'-TCAACTCCGCTGAAAGGG TCCG-5'. Briefly, $10 \mu \mathrm{g}$ nuclear extract was added to $20 \mathrm{fmol}$ biotin-labeled oligonucleotides, $1 \mathrm{X}$ binding buffer, $2.5 \%$ Glycerol, $5 \mathrm{mM} \mathrm{MgCl}_{2}, 0.1 \mathrm{mM}$ EDTA and $0.05 \% \mathrm{NP}-40$ at $24^{\circ} \mathrm{C}$ for $40 \mathrm{~min}$. The reactions were analyzed by electrophoresis on $5 \%$ polyacrylamide gels in $0.5 \mathrm{X}$ TBE buffer at $180 \mathrm{~V}$ for $35 \mathrm{~min}$, and were transferred to positively-charged nylon membranes and cross-linked in a Stratagene cross-linker (Agilent Technologies, Inc., Santa Clara, CA, USA). The signals were visualized using chemiluminescent detection (Beyotime Institute of Biotechnology) on X-ray film.

Western blotting assay. H292 cells and differentiated THP-1 cells were stimulated with $1 \mu \mathrm{g} / \mathrm{ml}$ LPS for $24 \mathrm{~h}$. Cells were washed with ice-cold PBS and then lysed with radio-immunoprecipitation assay lysis buffer (Beijing Solarbio Science \& Technology Co., Ltd.). Protein concentration was determined using a BCA protein assay. Samples containing $30 \mu \mathrm{g}$ of protein were mixed with SDS sample buffer and boiled. Protein was separated by $10 \%$ SDS-polyacrylamide gel electrophoresis prior to being transferred electrophoretically into polyvinylidene fluoride membrane. The membranes were blocked for $1.5 \mathrm{~h}$ at room temperature with $5 \%$ nonfat milk and then incubated with primary antibodies at $4^{\circ} \mathrm{C}$ overnight followed by incubation with horseradish peroxidase (HRP)-conjugated secondary antibodies for $1 \mathrm{~h}$ at $22^{\circ} \mathrm{C}$. The bands were visualized by film exposure following incubation with enhanced chemiluminescence reagent (Beijing Solarbio Science \& Technology Co., Ltd.). Antibodies used were as follows: Anti-TLR4 (Proteintech Group, Inc., Chicago, IL, USA; cat. no. 19811-1-AP; 1:500), anti-inhibitor of $\kappa \mathrm{B} \alpha(\mathrm{I} \kappa \mathrm{B} \alpha$; Proteintech Group, Inc.; cat. no. 10268-1-AP; 1:500), anti-p65 (Proteintech Group, Inc.; cat. no. 10745-1-AP; 1:500), anti-p38 (Proteintech Group, Inc.; cat. no. 14064-1-AP; 1:500), anti-Jun proto-oncogene AP-1 transcription factor subunit (JUN; Proteintech Group, Inc.; cat. no. 10024-2-AP; 1:500), anti-JAK1 (Proteintech Group, Inc.; cat. no. 66466-1-Ig; 1:500), 

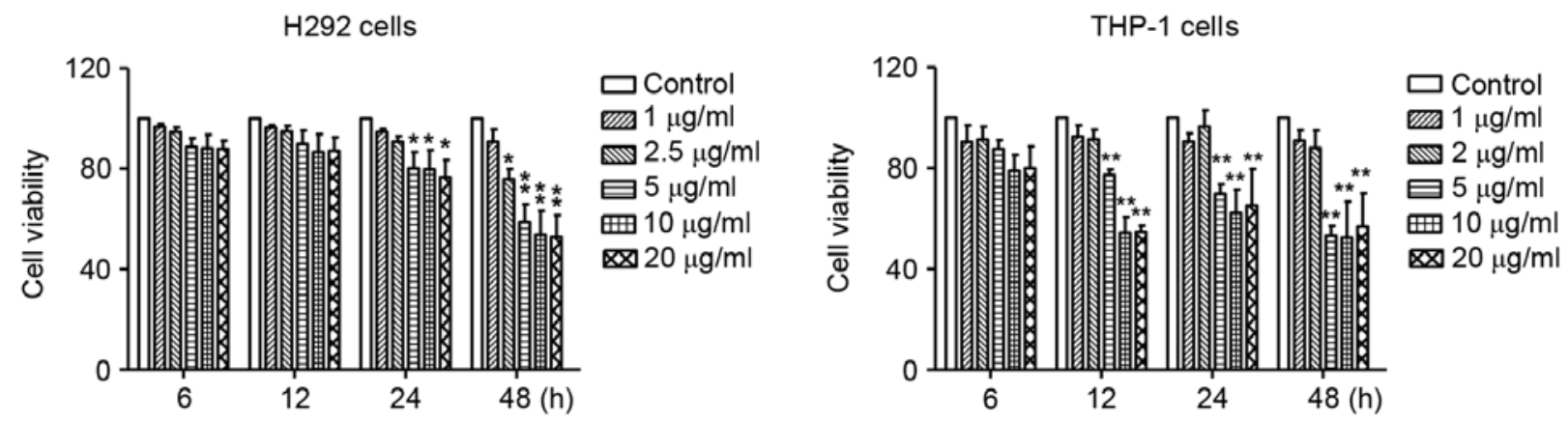

Figure 1. Effects of LPS stimulation on cell viability of H292 and THP-1 cells. Cells were stimulated with the indicated concentrations of LPS for 6, 12, 24 or $48 \mathrm{~h}$, then cell viability was evaluated by MTT assay. Untreated cells were used as control. Results were expressed as mean \pm standard deviation of three separate experiments. ${ }^{*} \mathrm{P}<0.05$ and ${ }^{* *} \mathrm{P}<0.01$ vs. control of each time point. LPS, lipopolysaccharide.
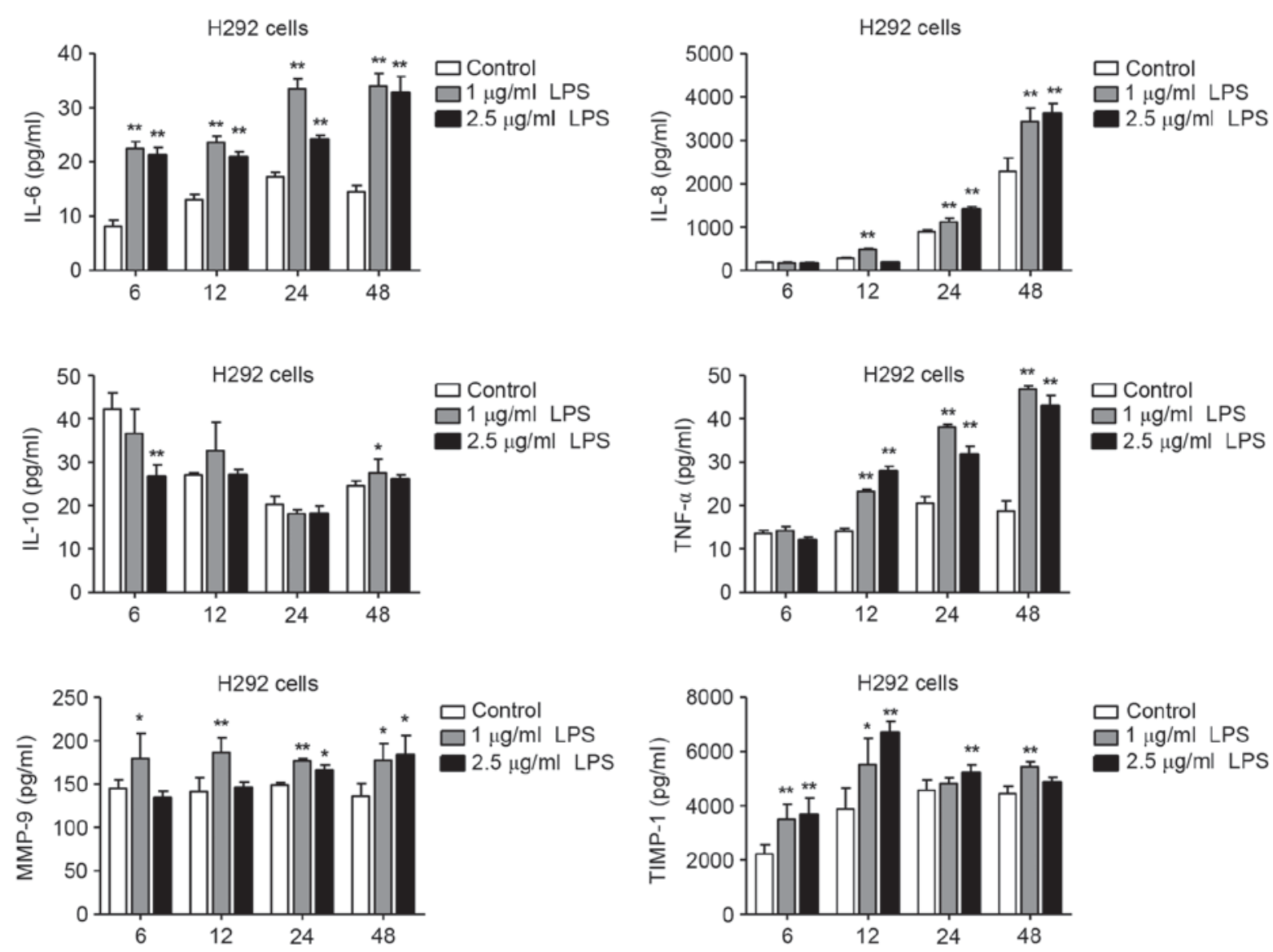

Figure 2. Effects of LPS stimulation on cytokine production of H292 cells. H292 cells were treated with 1 and $2.5 \mu \mathrm{g} / \mathrm{ml} \mathrm{LPS}$ for $6,12,24,48 \mathrm{~h}$, and protein production was assessed by ELISA. Results were expressed as mean \pm standard deviation of three separate experiments. ${ }^{*} \mathrm{P}<0.05$ and ${ }^{* * *} \mathrm{P}<0.01$ vs. control of each time point. LPS, lipopolysaccharide; IL, interleukin; TNF, tumor necrosis factor; MMP, matrix metallopeptidase; TIMP, tissue inhibitor of metalloproteinases.

anti-JAK2 (Proteintech Group, Inc.; cat. no. 17670-1-AP; $1: 500$ ), anti- $\beta$-actin rabbit polyclonal antibody (Proteintech Group, Inc.; cat. no. 20536-1-AP; 1:4,000), anti-p-STAT3 (Bioworld Technology, Inc., St Louis Park, MN, USA; cat. no. BS4181; 1:800), anti-p-p65 (Bioworld Technology, Inc.; cat. no. BS5088, 1:600), anti-p-p38 (Bioworld Technology, Inc.; cat. no. 4522; 1:500), HRP-conjugated Affinipure goat anti-mouse $\operatorname{IgG}(\mathrm{H}+\mathrm{L}$ ) (Proteintech Group, Inc.; cat. no. SA00001-1; 1:5,000) and HRP-conjugated Affinipure Goat Anti-Rabbit $\operatorname{IgG}(\mathrm{H}+\mathrm{L})$ (Proteintech Group, Inc.; cat. no. SA00001-2; 1:5,000).
Statistical analysis. Data were presented as mean \pm standard error. Results were analyzed by one-way analysis of variance followed by Tukey's range test using the SPSS 17.0 software package (SPSS, Inc., Chicago, IL, USA). $\mathrm{P}<0.05$ was considered to indicate a statistically significant difference.

\section{Results and Discussion}

Effect of LPS exposure on cell viability. First, the cytotoxic effects of LPS were determined by MTT assay in human lung mucoepidermoid carcinoma H292 cells and monocyte 

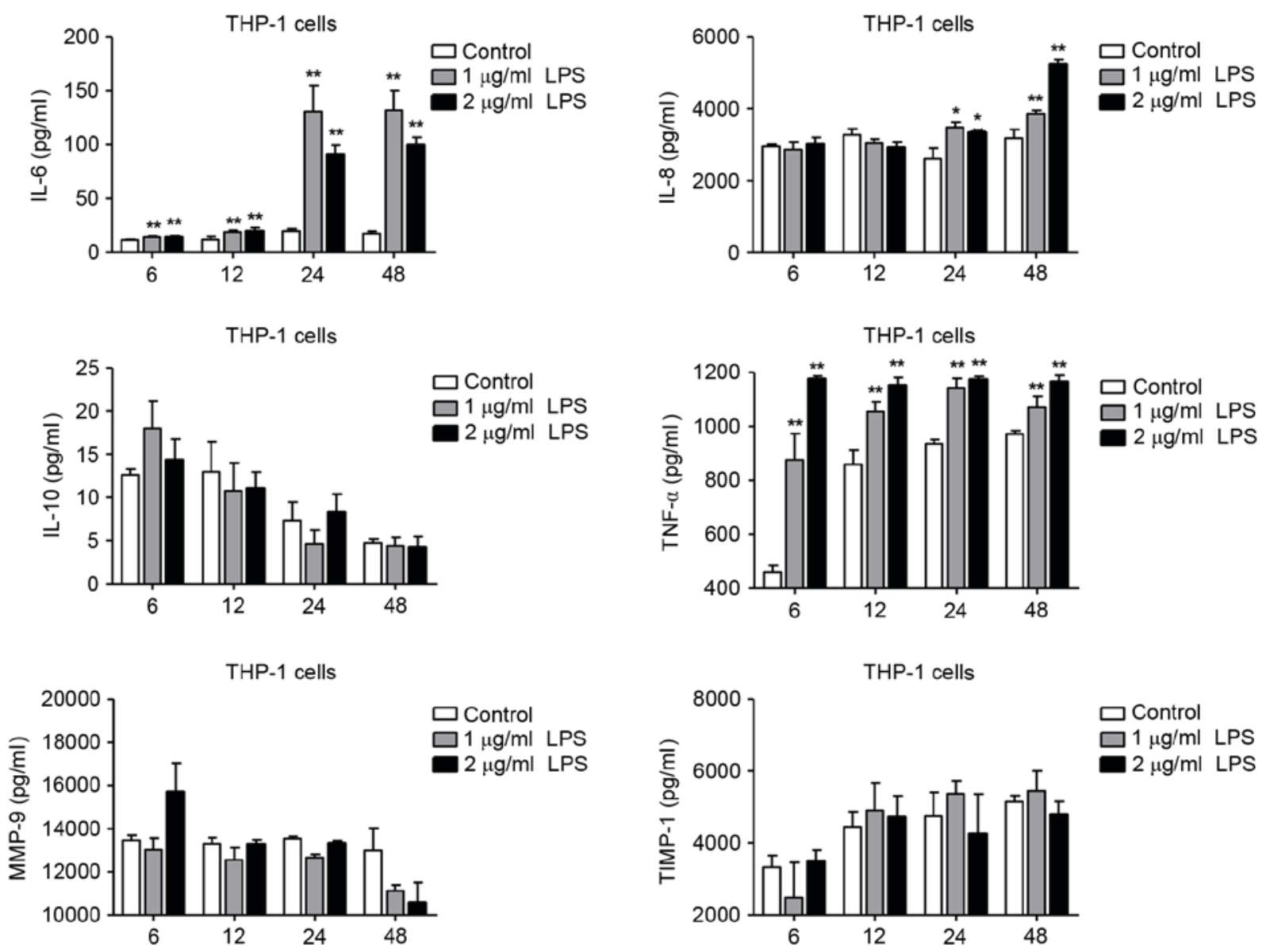

Figure 3. Effects of LPS stimulation on cytokine production of THP-1 cells. THP-1 cells were treated with 1 and $2 \mu \mathrm{g} / \mathrm{ml}$ LPS for $6,12,24,48 \mathrm{~h}$, and protein production was assessed by ELISA. Results were expressed as mean \pm standard deviation of three separate experiments. $\mathrm{P}<0.05$ and ${ }^{* * *} \mathrm{P}<0.01$ vs. control of each time point. LPS, lipopolysaccharide; IL, interleukin; TNF, tumor necrosis factor; MMP, matrix metallopeptidase; TIMP, tissue inhibitor of metalloproteinases.

THP-1 cells treated with various concentrations of LPS for 6, 12, 24 and 48 h. As illustrated in Fig. 1, compared with the untreated controls, no significant change was observed in the viability of $\mathrm{H} 292$ cells treated with 1 and $2.5 \mu \mathrm{g} / \mathrm{ml} \mathrm{LPS}$, and the viability of THP-1 cells treated with 1 and $2 \mu \mathrm{g} / \mathrm{ml}$ LPS, indicating that LPS was not cytotoxic at these concentrations. Higher concentration $(5-20 \mu \mathrm{g} / \mathrm{ml})$ of LPS were significantly cytotoxic to both H292 and THP-1 cells (Fig. 1). Therefore, the concentrations of 1-2.5 and $1-2 \mu \mathrm{g} / \mathrm{ml}$ were selected for $\mathrm{H} 292$ and THP-1 cells, respectively, in all subsequent experiments.

Levels of IL-6, -8, -10, TNF- $\alpha$, MMP-9 and TIMP-1 in LPS-exposed H292 and THP-1 cells. LPS is a potent proinflammatory activator of monocytes and macrophages in vivo and in vitro $(3,12)$. In the present study, H292 and differentiated THP-1 cells were exposed to different concentrations of LPS for 6, 12, 24 and $48 \mathrm{~h}$, then the expression levels of IL-6, $-8,-10$, TNF- $\alpha$, MMP-9 and TIMP-1 were detected by ELISA. Compared with untreated $\mathrm{H} 292$ cells, treatment with 1 and $2.5 \mu \mathrm{g} / \mathrm{ml}$ LPS resulted in increased levels of IL-6, -8 , TNF- $\alpha$, MMP-9 and TIMP-1 (Fig. 2). IL-10 levels in the LPS-treated H292 cells, however, were not significantly altered (Fig. 2). In differentiated THP- 1 cells, stimulation with 1 and $2 \mu \mathrm{g} / \mathrm{ml}$ LPS resulted in an increase of IL- $6,-8$ and TNF- $\alpha$ levels compared with control (Fig. 3). However, the expression levels of IL-10, MMP-9 and TIMP-1 were not significantly altered in THP-1 cells following LPS stimulation (Fig. 3). These results demonstrated that LPS could induce IL-6, -8 , and TNF- $\alpha$ expression in both the H292 and THP-1 cells. In addition, LPS treatment significantly increased the expression levels of MMP-9 and TIMP-1 in H292 cells, but not in differentiated THP-1 cells. Taken together, these data suggest that LPS stimulation had the different effects on cytokine expression profiles in H292 and differentiated THP-1 cells, and this may be related to differences in the physiological characteristics of these two cell types. H292 cells have characteristics similar to those of alveolar and bronchiolar epithelial cells and are widely used in alveolar and bronchiolar epithelial models, and the gene expression profile of $\mathrm{H} 292$ cells is similar to that of primary nasal epithelial cells from healthy human controls (13). THP-1 cells, a human leukemia-derived monocytic cell line, is the most commonly used cellular model for investigating human macrophage function (12).

Effect of LPS treatment on NF- $\kappa B, A P-1, P P A R$ and STAT3 $D N A$-binding activity. The transcription factors $\mathrm{NF}-\kappa \mathrm{B}$, AP-1, PPAR and STAT3 are the main signal transduction molecules activated in response to LPS-induced inflammatory response $(12,14)$. For example, NF- $\kappa \mathrm{B}$ translocates to the nucleus and promotes the transcription of proinflammatory genes, including the biologically active cytokine TNF- $\alpha$ and proinflammatory interleukins in activated macrophages (14). 

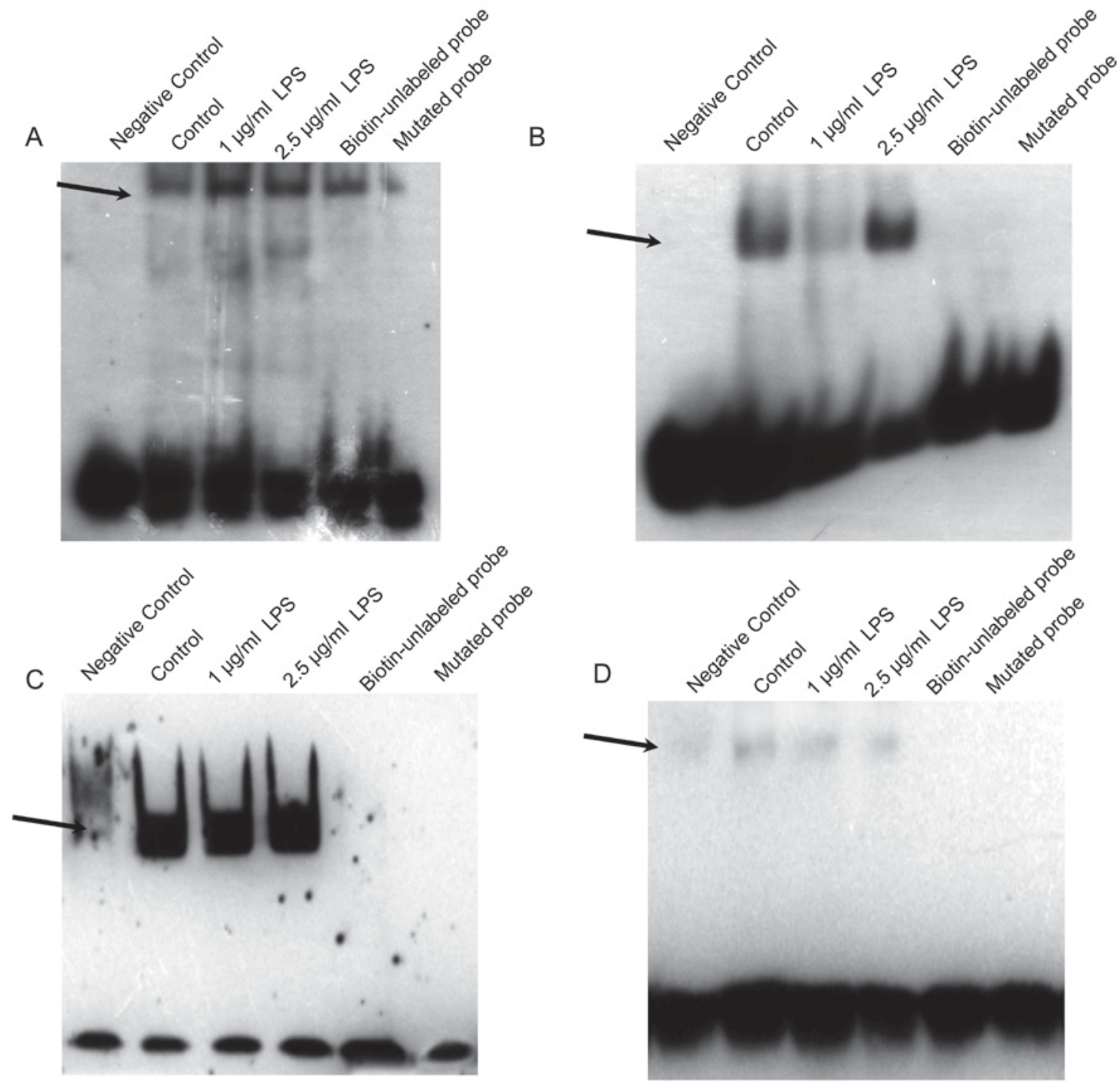

Figure 4. Effects of LPS stimulation on NF-kB, AP-1, PPAR and STAT3 DNA-binding activity in H292 cells. Nuclear extracts were prepared from H292 cells and EMSA was performed by incubation of extracts with the (A) NF- $\mathrm{kB}$, (B) AP-1, (C) PPAR or (D) STAT3 DNA-binding consensus sequences. Negative control, the biotin-labelled DNA oligo probe run without any protein extract; biotin-unlabeled protein, the biotin-unlabelled DNA oligo probe run with protein extract; mutated probe, the biotin-labelled DNA oligo probe with binding site mutation, run with protein extract. A total of three separate experi-

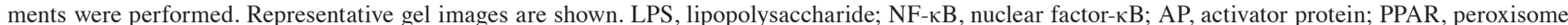
proliferator-activated receptor; STAT, signal transducer and activator of transcription.

Thus, the activation of NF-kB, AP-1, PPAR and STAT3 was investigated in $\mathrm{H} 292$ and THP-1 cells stimulated with LPS by EMSA. As illustrated in Fig. 4, treatment of H292 cells with 1or $2.5 \mu \mathrm{g} / \mathrm{ml}$ LPS for $24 \mathrm{~h}$ markedly increased the NF- $\kappa \mathrm{B}$ and AP-1 binding activities, but had no effect on the PPAR and STAT3 binding activities. Treatment of differentiated THP-1 cells with 1 and $2 \mu \mathrm{g} / \mathrm{ml}$ LPS for $24 \mathrm{~h}$ markedly increased the NF- $\mathrm{B}$ and STAT3 binding activities, slightly increased the AP-1 binding activity, but had no effect on PPAR (Fig. 5). These data indicated that LPS-induced cytokine expression in $\mathrm{H} 292$ cells likely resulted from the activation of the NF- $\kappa$ B and AP-1 transcription factors. Similarly, LPS-mediated cytokine expression in THP-1 cells was associated with the activation of the NF- $\mathrm{B}, \mathrm{AP}-1$ and STAT3 transcription factors.

Effect of LPS exposure on the NF- $\kappa B, M A P K$ and STAT3 signaling pathways. The activation of $N F-\kappa B$ signaling increases the I $\kappa \mathrm{B}$ phosphorylation or degradation, and subsequent $\mathrm{NF}-\kappa \mathrm{B}$ transactivation, translocation and promoter binding (15). In addition, $N F-\kappa B$ activation in the airways of allergen-challenged mice is attenuated by Toll-like receptor (TLR) 2 or TLR4 gene deletion, suggesting that TLR 2 or TLR4 contribute to NF- $\mathrm{B}$ signaling $(16,17)$. Similarly, the AP-1 and STAT3 promoter-binding activity are regulated by MAPK and JAK/STAT signaling $(18,19)$. Therefore, it was hypothesized that LPS may induce NF- $\kappa$ B, MAPK and JAK/STAT pathway activation, leading to NF- $\kappa \mathrm{B}, \mathrm{AP}-1$ and STAT3 nuclear translocation and cytokine expression in the H292 and THP-1 cells investigated in the present study.

In order to further examine the effects of LPS on pathway activation in H292 and THP-1 cells, cells were treated with $1 \mu \mathrm{g} / \mathrm{ml}$ LPS and the activation of NF- $\kappa \mathrm{B}$ and MAPK signaling pathways in $\mathrm{H} 292$ cells, and the activation of $\mathrm{NF}-\kappa \mathrm{B}$ and JAK/STAT3 signaling pathways in THP-1 cells, were 
A

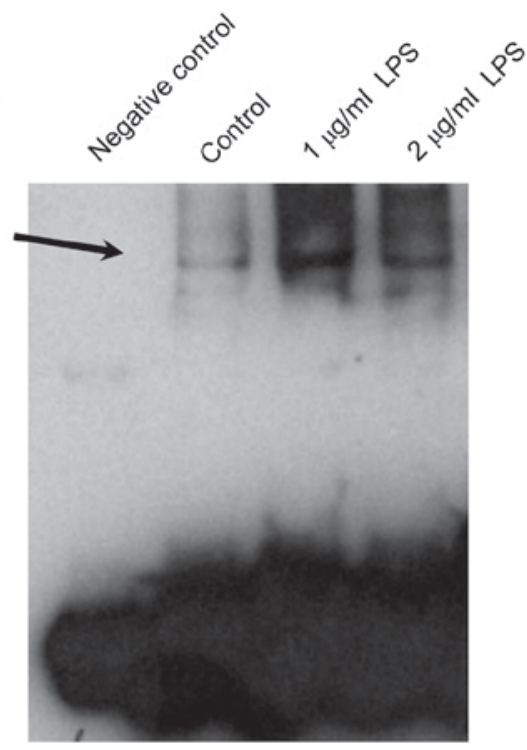

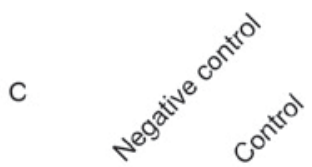
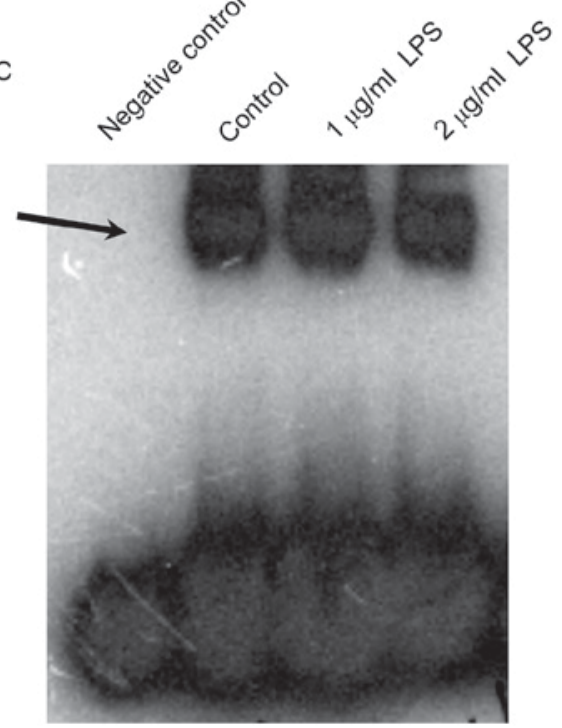

B
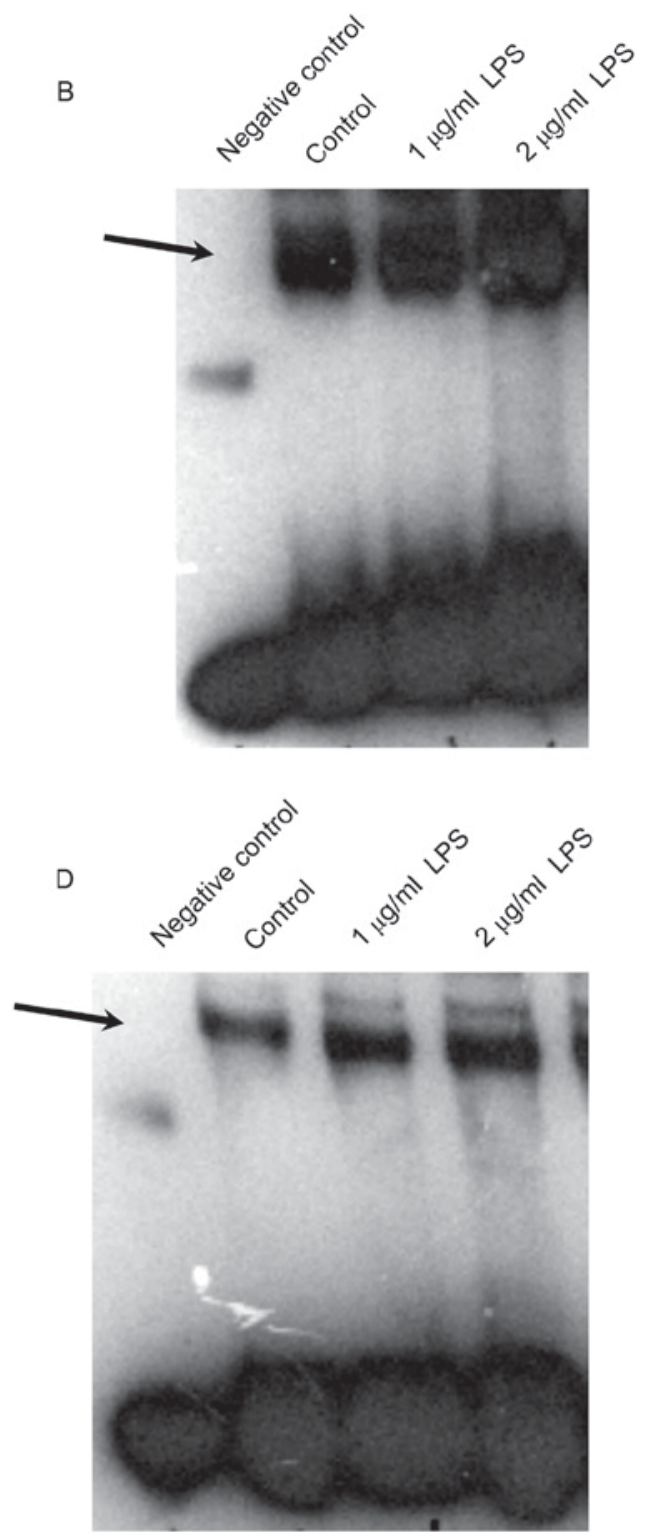

Figure 5. Effects of LPS stimulation on NF- $\kappa$ B, AP-1, PPAR and STAT3 DNA-binding activity in THP-1 cells. Nuclear extracts were prepared from the THP-1 cells and EMSA was performed by incubation of extracts with the (A) NF- $\kappa$ B, (B) AP-1, (C) PPAR and (D) STAT3 DNA-binding consensus sequences. Negative control, the biotin-labelled DNA oligo probe run without any protein extract. A total of three separate experiments were performed. Representative gel images are shown. LPS, lipopolysaccharide; NF- $\kappa \mathrm{B}$, nuclear factor- $\mathrm{B}$; AP, activator protein; PPAR, peroxisome proliferator-activated receptor; STAT, signal transducer and activator of transcription.

tested by western blotting. As the results demonstrated, LPS treatment for $24 \mathrm{~h}$ resulted in an obvious increase in $\mathrm{p} 65$ and p38 phosphorylation, as well as a marked increase in TLR4, $\mathrm{I} \kappa \mathrm{B} \alpha, \mathrm{p} 65, \mathrm{p} 38$ and JUN protein expression levels in $\mathrm{H} 292$ cells (Fig. 6A). In the differentiated THP-1 cells, LPS treatment for $24 \mathrm{~h}$ resulted in a marked increase of STAT3 and p65 phosphorylation, as well as an increase in TLR4, I $\mathrm{B} \alpha$ and Janus kinase (JAK) 1 protein expression levels, while JAK2 expression was not altered (Fig. 6B). These results indicated that $N F-\kappa B$, MAPK and their downstream signals were activated in H292 cells, while NF- $\mathrm{BB}$ and STAT3 downstream signals were activated in THP-1 cells following LPS exposure.

LPS has been reported to bind to the TLR4 receptor, and to induce activation of the NF- $\kappa \mathrm{B}$ pathway which then results in the release of proinflammatory cytokines (20). In the present study, LPS treatment was demonstrated to increase TLR4 expression in both $\mathrm{H} 292$ and THP-1 cells, and to activate $\mathrm{NF}-\kappa \mathrm{B}$ and MAPK signaling in $\mathrm{H} 292$ cells and $\mathrm{NF}-\kappa \mathrm{B}$ and STAT3 signaling in THP-1 cells. These findings suggested that LPS may bind to TLR4 receptor and activate different pathways in the human airway H292 and the human macrophage THP-1 cells.

Treatment with $N F-\kappa B, S T A T 3$ and AP-1 inhibitors reverses the LPS-induced cytokine expression. The role of the $\mathrm{NF}-\kappa \mathrm{B}$, AP-1 or STAT3 pathway activation in the LPS-mediated cytokine expression in $\mathrm{H} 292$ and differentiated THP-1 cells was further explored. H292 and THP-1 cells were pretreated with PDTC (a NF- $\mathrm{BB}$ inhibitor; $100 \mu \mathrm{M}$ ), SP00125 (an AP-1 inhibitor; $100 \mu \mathrm{M}$ ) or stattic (a STAT3 inhibitor; $100 \mu \mathrm{M}$ ) for $4 \mathrm{~h}$, followed by exposure to LPS for $48 \mathrm{~h}$. The results demonstrated that treatment with PDTC or SP00125 significantly 
A

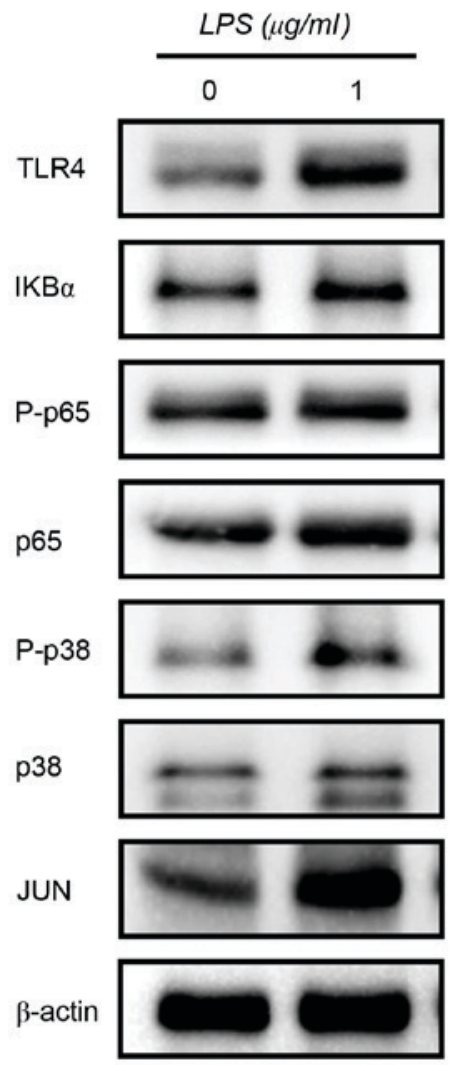

B

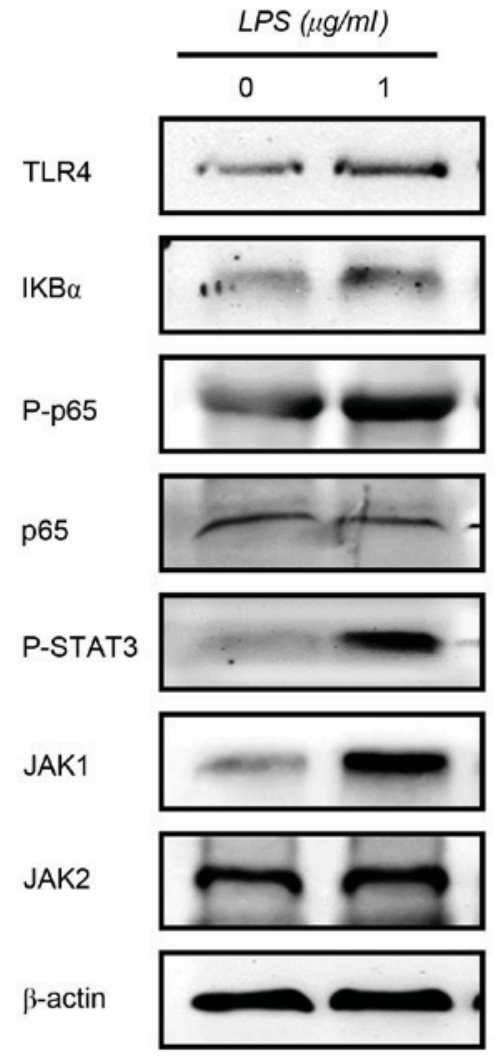

Figure 6. Effect of LPS stimulation on the NF-кB, MAPK and STAT3 signaling pathways. (A) H292 and (B) THP-1 cells were treated with $1 \mu \mathrm{g} / \mathrm{ml} \mathrm{LPS}$ for $24 \mathrm{~h}$ and protein expression levels of the indicated signaling molecules were examined by western blotting. Representative images are shown from three

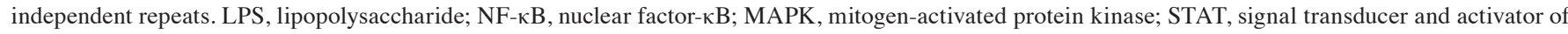
transcription; TLR, Toll-like receptor; IKB, inhibitor of $\kappa \mathrm{B}$; P-, phosphorylated; p65, RELA proto-oncogene NF- $\mathrm{B}$ s subunit; p38, mitogen-activated protein kinase 14; JUN, Jun proto-oncogene AP-1 transcription factor subunit; JAK, Janus kinase.

A

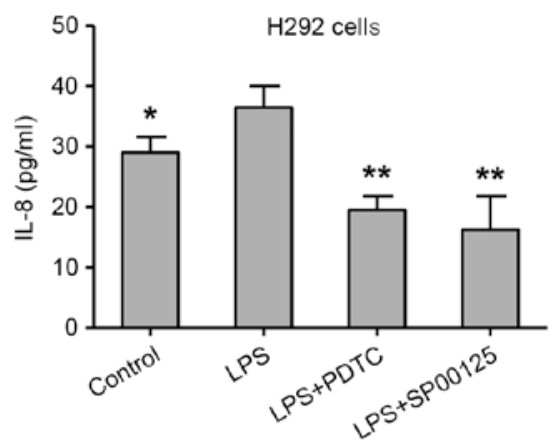

B

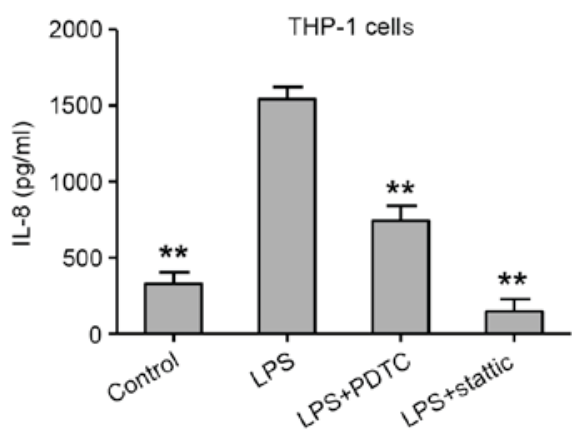

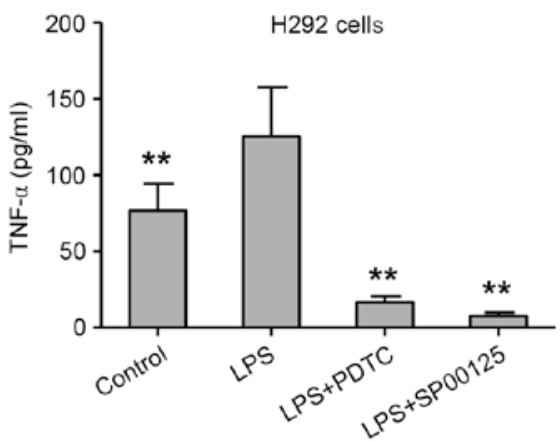

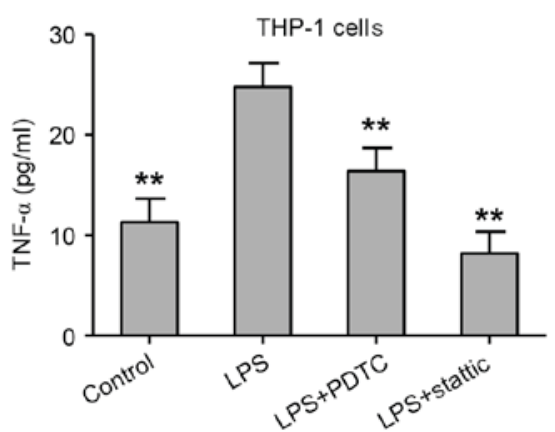

Figure 7. Role of NF-kB, AP-1 and STAT3 signaling in LPS-mediated cytokine production. (A) H292 and (B) THP-1 cells were pretreated with or without PDTC, SP00125 or stattic for $4 \mathrm{~h}$. Then, cells were exposed to $1 \mu \mathrm{g} / \mathrm{ml}$ LPS for $48 \mathrm{~h}$, and expression levels of IL- 8 or TNF- $\alpha$ were analyzed by ELISA. Results were expressed as mean \pm standard deviation of three separate experiments. ${ }^{*} \mathrm{P}<0.05$ and ${ }^{* *} \mathrm{P}<0.01$ vs. LPS alone. LPS, lipopolysaccharide; NF- $\mathrm{BB}$, nuclear factor- $\mathrm{kB}$; AP, activator protein; STAT, signal transducer and activator of transcription; PDTC, pyrrolidine dithiocarbamate. 
inhibited the LPS-induced expression of IL- 8 and TNF- $\alpha$ in $\mathrm{H} 292$ cells, compared with cells treated with LPS alone (Fig. 7A). Similarly, treatment with PDTC or stattic significantly decreased the LPS-induced expression of IL-8 and TNF- $\alpha$ in THP-1 cells, compared with cells treated with LPS alone (Fig. 7B). These results suggest that NF- $\kappa \mathrm{B}, \mathrm{AP}-1$ or STAT3 signaling might serve critical roles in LPS-mediated cytokine expression in lung epithelial cells and macrophages.

In conclusion, LPS stimulation increased the production of IL-6, IL-8, TNF- $\alpha$, MMP-9 and TIMP-1 in H292 cells, and it increased the expression of IL-6, IL-8, and TNF- $\alpha$ in THP-1 cells. In addition, LPS stimulation increased the DNA-binding activation of NF- $\mathrm{KB}$ and AP-1 in $\mathrm{H} 292$ cells, and the DNA-binding activation of NF- $\kappa$ B and STAT3 in THP-1 cells. NF- $\kappa$ B, MAPK and STAT3 downstream signaling was also activated by LPS stimulation. Furthermore, NF- $\kappa$ B, AP-1 or STAT3 inhibitors significantly reversed the LPS-mediated IL- 8 and TNF- $\alpha$ induction in H292 and THP-1 cells. The present study suggests that these signals might serve vital roles in LPS-induced cytokine expression in human airway cells and macrophages.

\section{Acknowledgements}

The authors of the present study would like to acknowledge financial support from the National Natural Science Fund of China (Influence and Long-Term Effects of Three Tiao-Bu Fei-Shen Therapies in Rats with Chronic Obstructive Pulmonary Disease on Regulation of Multidimensional Molecular Network; grant no. 81130062), Outstanding TCM Academic Leader Program of Henan Province (grant no. HNZYLJ201301001), and Scientific and Technological Leading Talent Projects of Zhengzhou (grant no. 131PJRC659).

\section{Competing interests}

The authors declare that they have no competing interests.

\section{References}

1. Eisner MD, Anthonisen N, Coultas D, Kuenzli N, Perez-Padilla R, Postma D, Romieu I, Silverman EK and Balmes JR; Committee on Nonsmoking COPD, Environmental and Occupational Health Assembly: An official American Thoracic Society public policy statement: Novel risk factors and the global burden of chronic obstructive pulmonary disease. Am J Respir Crit Care Med 182: 693-718, 2010.

2. Dohrman A, Miyata S, Gallup M, Li JD, Chapelin C, Coste A, Escudier E, Nadel J and Basbaum C: Mucin gene (MUC 2 and MUC 5AC) upregulation by Gram-positive and Gram-negative bacteria. Biochim Biophys Acta 1406: 251-259, 1998.

3. Hasday JD, Bascom R, Costa JJ, Fitzgerald T and Dubin W: Bacterial endotoxin is an active component of cigarette smoke. Chest 115: 829-835, 1999.

4. Li L, Wang Y, Gao W, Yuan C, Zhang S, Zhou H, Huang M and Yao X: Klotho reduction in alveolar macrophages contributes to cigarette smoke Extract-induced inflammation in chronic obstructive pulmonary disease. J Biol Chem 290: 27890-27900, 2015.
5. Tseng CT, Perrone LA, Zhu H, Makino S and Peters CJ: Severe acute respiratory syndrome and the innate immune responses: Modulation of effector cell function without productive infection. J Immunol 174: 7977-7985, 2005.

6. Ursini CL, Cavallo D, Fresegna AM, Ciervo A, Maiello R Tassone P, Buresti G, Casciardi S and Iavicoli S: Evaluation of cytotoxic, genotoxic and inflammatory response in human alveolar and bronchial epithelial cells exposed to titanium dioxide nanoparticles. J Appl Toxicol 34: 1209-1219, 2014.

7. Speth JM, Bourdonnay E, Penke LR, Mancuso P, Moore BB, Weinberg JB and Peters-Golden M: Alveolar epithelial cell-derived prostaglandin E2 serves as a request signal for macrophage secretion of suppressor of cytokine signaling 3 during Innate Inflammation. J Immunol 196: 5112-5120, 2016.

8. Li YJ, Yu CH, Li JB and Wu XY: Andrographolide antagonizes cigarette smoke extract-induced inflammatory response and oxidative stress in human alveolar epithelial A549 cells through induction of microRNA-218. Exp Lung Res 39: 463-471, 2013.

9. Zeng KW, Wang S, Dong X, Jiang Y, Jin HW and Tu PF: Sesquiterpene dimmer (DSF-27) inhibits the release of neuroinflammatory mediators from microglia by targeting spleen tyrosine kinase (Syk) and Janus kinase 2 (Jak2): Two major non-receptor tyrosine signaling proteins involved in inflammatory events. Toxicol Appl Pharmacol 275: 244-256, 2014.

10. Singh D, Siew L, Christensen J, Plumb J, Clarke GW, Greenaway S, Perros-Huguet C, Clarke N, Kilty I and Tan L: Oral and inhaled p38 MAPK inhibitors: Effects on inhaled LPS challenge in healthy subjects. Eur J Clin Pharmacol 71: 1175-1184, 2015.

11. Xu F, Xu Y, Zhu L, Rao P, Wen J, Sang Y, Shang F and Liu Y: Fasudil inhibits LPS-induced migration of retinal microglial cells via regulating p38-MAPK signaling pathway. Mol Vis 22: 836-846, 2016.

12. Lund ME, To J, O'Brien BA and Donnelly S: The choice of phorbol 12-myristate 13-acetate differentiation protocol influences the response of THP-1 macrophages to a pro-inflammatory stimulus. J Immunol Methods 430: 64-70, 2016.

13. Vroling AB, Jonker MJ, Breit TM, Fokkens WJ and van Drunen CM: Comparison of expression profiles induced by dust mite in airway epithelia reveals a common pathway. Allergy 63: 461-467, 2008.

14. Yamamoto Y and Gaynor RB: Role of the NF-kappaB pathway in the pathogenesis of human disease states. Curr Mol Med 1: 287-296, 2001.

15. Hart LA, Krishnan VL, Adcock IM, Barnes PJ and Chung KF: Activation and localization of transcription factor, nuclear factor-kappaB, in asthma. Am J Respir Crit Care Med 158: 1585-1592, 1998.

16. Lam D, Ng N, Lee S, Batzer G and Horner AA: Airway house dust extract exposures modify allergen-induced airway hypersensitivity responses by TLR4-dependent and independent pathways. J Immunol 181: 2925-2932, 2008.

17. Li X, Chen Q, Chu C, You H, Jin M, Zhao X, Zhu X, Zhou W and Ji W: Ovalbumin-induced experimental allergic asthma is Toll-like receptor 2 dependent. Allergy Asthma Proc 35: e15-e20, 2014.

18. Yew-Booth L, Birrell MA, Lau MS, Baker K, Jones V, Kilty I and Belvisi MG: JAK-STAT pathway activation in COPD. Eur Respir J 46: 843-845, 2015.

19. Luff SA and Papoutsakis ET: Megakaryocytic maturation in response to shear flow is mediated by the activator protein 1 (AP-1) transcription factor via Mitogen-activated protein kinase (MAPK) mechanotransduction. J Biol Chem 291: 7831-7843, 2016.

20. Kagan JC and Medzhitov R: Phosphoinositide-mediated adaptor recruitment controls Toll-like receptor signaling. Cell 125: 943-955, 2006. 